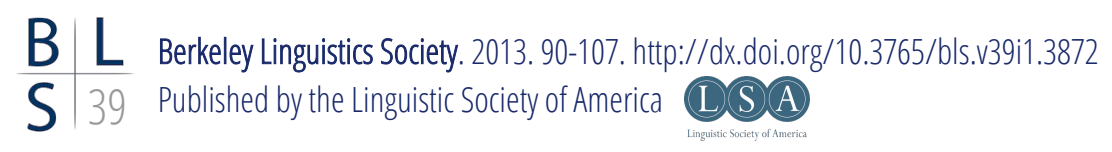

\title{
Quantifier Float, Focus, and Scope in Thai
}

Peter Jenks

University of California, Berkeley

\section{Introduction}

There are two divergent views on the proper analysis of Q(uantifier)-float. On one hand, the adverbial position of floated quantifiers (FQs) indicates that they are verbal adjuncts (Dowty and Brodie 1984, Bobaljik 1995, Doetjes 2007, Nakanishi 2007). On the other hand, locality restrictions on Q-float support the idea that it involves movement (Belletti 1982, Kayne 1984, Sportiche 1988, Miyagawa 1989, Miyagawa and Arikawa 2007).

Q-float in Thai is no exception. Adverbs occur at the right edge of the VP, and this is where we find FQs in Thai as well, as (1b) shows.
a. nák.rian thúk-khon [vP Paan nàgš̌u] mûtawaanníi student every-CLF ${ }^{\text {person }}$ read book yesterday
b. nák.rian [VP Paan nàysǔu] mûuawaanníi thúk-khon student read book every-CLF yesterday (both) 'Every student read a book.'

At the same time, there are syntactic restrictions on which nouns can host FQs. For example, while objects can host FQs (2a), genitive NPs cannot (2b):
a. Pong cà [VP hây [DP năysǔu khǒoy dèk thúk-khon] kàp Nít ] Pong IRR give book POS child every-CLF to Nit 'Pong will give every child's book to Nit.'




\section{Peter Jenks}

\section{b. *Pong cà [ [VP hây [DP năysǔu khǒon dèk ] kàp Nít ] thúk-khon Pong IRR give book POS child to Nit every-CLF}

The basic generalization, as we will see below, is that only nouns which are arguments of the main predicate can host FQs.

Another phenomenon, Quantifier Raising (QR) has been argued to account for inverse scope in examples like the following (May 1985):

(3) Some student read every book.

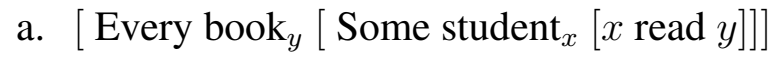

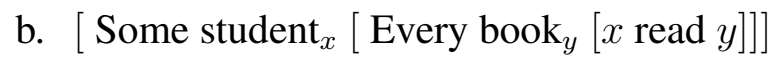

Quantifier Raising (QR) has been independently claimed to possess similar properties as Q-float. First, recent analyses of QR have been argued to target a position between VP and TP, often analyzed as an adjunct (Hornstein 1995, Beghelli and Stowell 1997, Johnson and Tomioka 1997, Fox and Nissenbaum 1999, Fox 2000). Second, QR is subject to locality constraints, applying within a CP or DP (May 1985, Reinhart 1997). I argue below that Q-float and QR share these properties because Thai Q-float is overt QR (Jenks 2011). I will show that Q-float from both subjects and objects in Thai targets a position adjoined to $v \mathrm{P}$, where it is interpreted. I propose that Q-float involves movement of the entire DP, and that it is only the pronunciation of these elements which is discontinuous. Unlike in the analysis of Jenks (2011), however, I will argue that Q-float is driven by focus on the floated quantifier, following Simpson (2011). This is unsurprising, as other rightward movement phenomena such as heavy-NP shift and subject inversion are associated with focus on the rightward element.

Section 2 outlines the basic properties of Q-float in Thai, including its effect on quantifier scope. Section 3 introduces the QR-based analysis of Q-float. Section 4 introduces the role of focus, and section 5 sketches how the focus facts can be integrated with the QR-based analysis of Q-float.

\section{Properties of Quantifier Float in Thai}

In this section I summarize three properties of Q-float in Thai, which will form the basis for my analysis. These properties are: 1) Q-float is general, meaning it is able to apply to any quantifier, 2) Q-float is sensitive to locality restrictions, reminiscent of movement phenomena 3) Q-float affects the scope of quantifiers relative to negation. The role of focus is discussed later, in section 4 .

\subsection{Locality Restrictions on Quantifier Float}

Q-float in Thai is quite free, as FQs can be associated with subjects (19b), direct objects (5), and indirect objects (6) (Wongbiasaj 1980): 
(4) SUBJECT QUANTIFIER FLOAT

a. nák.rian thúk-khon / săam-khon [VP Paan nàysǔu] mûuawaanníi

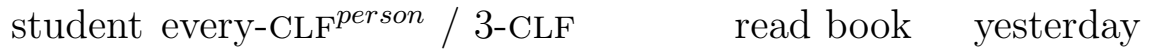

b. nák.rian [VP Paan nàysǔu] thúk-khon / săam-khon mûuawaanníi student read book every-CLF / 3-CLF yesterday

(both) 'All the students/Three students read a book.'

(5) OBJECT QUANTIFIER FLOAT

a. nák.rian [VP Paan nàysǔu thúk-lêm / săam-lêm] lécW

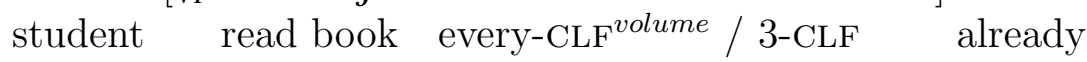

b. nák.rian [VP Paan nàyš̌u] lécW thúk-lêm / săam-lêm student read book already every-CLF / 3-CLF

(both) 'The students have already read every book/three books.'

(6) INDIRECT OBJECT QUANTIFIER FLOAT

a. Tát [vp hâi năysǔu ka? dèk thúk-khon pai ] Tat give book to child every-CLF ${ }^{\text {person }}$ PRF

b. Tát [vp hâi năgsǔu ka? dèk pai ] thúk-khon Tat give book to child PRF every-CLF ${ }^{\text {person }}$ (both) 'Tat gave books away to every child.'

Regardless of the position of its nominal host, Thai FQs appear in a position on the right edge of the clause, basically the same position where adverbs appear.

As was discussed in the introduction, however, there are clear locality restrictions on Q-float. Thus, quantifiers cannot float from genitives (7), noun complements (8):

(7) No Q-FLOAT FROM GENITIVES

a. Pong cà [VP hây [DP năyš̌H khǒoy dèk săam-khon ] kàp Nít ] Pong IRR give book POS child 3-CLF to Nit 'Pong will give the three children's book to Nammon tomorrow.'

b. * Pong cà [VP hây [DP năyš̌u khǒondèk ] kàp Nít ] săam-khon Pong IRR give book POS child to Nit 3-CLF

(8) No Q-FLOAT FROM NOUN COMPLEMENTS

a. Jôo wâat [DP phâap măa săam-tua ] lécw

Joe draw picture dog 3-CLF ${ }^{\text {animal }}$ already

'Joe drew three pictures of dogs already.'

b. * Jôo wâat [DP phâap măa] lécw săam-tua Joe draw picture dog already 3-CLF

Q-float also cannot apply out of relative clauses (Simpson 2004, ex. 43): 


\section{Peter Jenks}

(9) No Q-FLOAT OUT OF RELATIVE CLAUSES

a. phǒm khəəj сәə [DP phûu-chaaj [CP thîi mii rót kwaa-sìp-khan ]] I PRF meet man REL have car exceed-10-CLF maa lécw.

ASP already

'I have met men who have owned more than 10 cars.'

b. * phǒm khəəj cəə [DP phûu-chaaj [CP thîi mii rót ]] maa léعw I PRF meet man REL have car ASP already kwaa-sìp-khan. exceed-10-CLF

Finally, Q-float cannot be hosted by a noun phrase contained within an adjunct PP (Wongbiasaj 1980):

(10) NO Q-FLOAT OUT OF PREPOSITIONAL PHRASES

a. Bill róp nai sanăamróp thúk-hey yàay-klâahăan Bill fight in battlefield every-CLF ${ }^{\text {place }}$ bravely 'Bill fought bravely in all the battlefields.'

b. * Bill róp nai sanăamróp yàay-klâahăan thúk-hey Bill fight in battlefield bravely every-CLF ${ }^{\text {place }}$

'Bill fought bravely in all the battlefields.'

The basic generalization which covers these examples is that Q-float can only be hosted by nominal arguments of the predicate to which the FQ attaches.

\subsection{All Quantifiers Can Float}

Quantifier float in Thai is not only liberal in the positions that can host quantifier float, but nearly all quantifiers can float in Thai, including strong quantificational determiners (19b), numerals (19b), modified numerals (11), and weak quantificational determiners (12):

nák-riian [ Paan năysǔu] săam-kwaa-khon

'More than three students read (a book).'
nák-riian [ kin khâaw lécw ] lăaj-khon
student eat rice already several-CLF
'Several students have already eaten.

All of the quantificational elements above must occur with a classifier, but at least one quantifier which does not require a classifier also floats, the universal quantifier tháy-mòt: 


\section{(13) nák-riian [ kin khâaw lécw ] tháy-mòt}

student eat rice already all-finish

'All the students are already asleep.'

This fact precludes the possibility that the ability for quantifiers to float in Thai is dependent on the presence of the classifier.

While nearly all of these quantifiers can float in Thai, the distributive operator tèclá?-khon 'each' cannot float:

$$
\begin{aligned}
& \text { a. nák-riian tį̀lá?-khon [ kin khâaw lécw ] } \\
& \text { student each-CLF eat rice already } \\
& \text { 'Each student read a book.' } \\
& \text { b. * nák-riian [ kin khâaw lécw ] tèclá?-khon } \\
& \text { student eat rice already each-CLF }
\end{aligned}
$$

In addition, the quantifier sùuan-mâak 'majority' cannot float:

$$
\begin{aligned}
& \text { a. nák-riian sùan-mâak [ kin khâaw lécw ] } \\
& \text { student part-many eat rice already } \\
& \text { 'Most students read a book.' } \\
& \text { b. * nák-riian [ kin khâaw lécw ] sùan-mâak } \\
& \text { student eat rice already part-many }
\end{aligned}
$$

There is reason to believe that neither of these elements are true quantifiers. The more obvious case is sùan-mâak 'majority,' literally 'part-a.lot.' English most is ambiguous between a majority reading and and relative reading, only the latter of which has quantificational semantics. Thai sùan-mâak lacks the relative reading (Boškovic̀ and Gajewski to appear). ${ }^{1}$ The other unfloatable element is tèz-láp-khon 'each,' literally 'but-per.' As the semantic components of this morpheme are associated with disjunction and distribution, I propose that tèc-lá?-khon is a distributive operator rather than a quantifier, leaving the details of this proposal for further work.

With these two cases put tentatively aside, I conclude that every element with clearly quantificational semantics can float in Thai. This means that whatever Thai Q-float is, it should be a process that applies to quantifiers generally.

\subsection{The Effect of Quantifier Float on Scope}

Q-float in Thai has a clear effect on quantifier scope relative to negation: ${ }^{2}$

(16) a. Q-float lowers the scope of subject quantifiers relative to negation.

b. Q-float raises the scope of object quantifiers relative to negation.

\footnotetext{
${ }^{1}$ According to Boškovic̀ and Gajewski (to appear), this is a property of languages which lack overt articles, which is true of Thai.

${ }^{2}$ Sentences with multiple quantifiers are more complex, allowing inverse readings regardless of whether Q-float applied.
} 


\section{Peter Jenks}

Evidence for the lowering effects of Q-float on subject quantifier comes from the indefinite quantifier sák, which is unavailable in subject position in Thai (17a), a fact which is related to the definiteness of Thai subjects (Ekniyom 1982). Below negation, this quantifier must have an NPI interpretation (17b):
a. * nák-riian sák-khon yạ mâj [vp kin khâaw] student even.one-CLF still NEG eat rice
'Not even one student has eaten.' (Intended)
b. Paacaan yạ mâj [ $\mathrm{VP}$ tii nák-riian sák-khon ] teacher still NEG hit student even.one-CLF
'Teachers haven't hit even one student'

Yet sák can occur as a subject-hosted FQ, saving (17a) and resulting in an NPI interpretation for the quantifier:
(18) nák-riian yạ mâj [ ${ }_{\mathrm{vP}}$ kin khâaw] sák-khon
student still NEG eat rice even.one-CLF

'Not even one student has eaten.'

Quantifier scope data point to the same conclusion. While subject Qs must scope above negation (19a), subject-hosted FQs can scope below negation (19b):

a. nák-riian thúk-khon (yạ) mâj [VP kin khâaw] student every-CLF still NEG eat rice 'Every student still hasn't eaten.' $\quad \forall>\neg, * \neg>\forall$

b. nák-riian (yạ) mâj [ ${ }_{\mathrm{VP}}$ kin khâaw] thúk-khon student still NEG eat rice every-CLF 'Every student still hasn't eaten.' $\quad \forall>\neg, \neg>\forall$

Q-float shows the opposite effect on object quantifiers. While quantifiers in object position must scope below negation (20a), object FQs can scope above negation (20b):

a. Joe mâj [vp phóp nákriian thúk-khon] mûuawaanníi Joe NEG meet student every-CLF yesterday 'Joe didn't meet all of the students yesterday' $\quad * \forall>\neg, \neg>\forall$

b. Joe mâj [Vp phóp nákriian] mûuawaanníi thúk-khon Joe NEG meet student yesterday every-CLF 'Joe didn't meet all of the students yesterday' $\quad \forall>\neg, \neg>\forall$

The scopal effects of Q-float from subject and object position relative to negation is summarized below: 
(21)

\begin{tabular}{llcc} 
& \multicolumn{1}{r}{$\forall>\neg$} & $\neg>\forall$ \\
\hline \hline Subject-Q & NP- $\forall \ldots \neg \ldots$ & $*$ \\
\hline Subject-FQ & NP $\ldots \neg \ldots \forall$ & & \\
\hline Object-Q & $\neg \ldots$ NP- $\forall \ldots$ & $*$ & \\
\hline Object-FQ & $\neg \ldots$ NP $\ldots \forall$ &
\end{tabular}

While the examples related to scope above are illustrated for universal quantifiers, these facts seem to be quite general, holding for both strong and weak quantifiers.

One pressing question is how to account for the scopal ambiguity of FQs relative to negation, the answer to which will reveal the structural position of the FQ. Assuming semantic scope is dependent on syntactic c-command (Reinhart 1983), there are two possibilities. First, the FQ might be attaching at two different positions, either above or below an invariant position for negation. Second, negation might be occurring in two positions, above or below the attachment site for FQs.

The position of negation is variable in Thai, lending plausibility to the second approach. First, Visonyangoon also argues that negation is a verbal specifier, as it does not license ellipsis, unlike other verbal heads (p. 132):

a. khăw dùu thiiwii, tèc chăn mâj duu 3 P watch T.V. but 1P.SG NEG watch 'He watches T.V. but I don't.'

b. *khăw dùu thiiwii, tèc chăn mâj 3P watch T.V. but 1P.SG NEG

She further demonstrates that negation can occur in multiple positions (p. 166):

(23) khăw mâj nâa-cà? mâj tôn mâj tham yaan

3P NEG should NEG must NEG do work

'It is unlikely that he does not have to not work.

In light of these facts, I take the variable scope of FQs in (19b) and (20b) to correspond to two positions for negation. Clausal negation is marked in the (inner) specifier of TP, while constituent negation of VP is marked in the specifier of VP. Assuming the FQ to be right-adjoined to an intermediate $v \mathrm{P}$, the two scopal possibilities of these examples are predicted:

STRUCTURES FOR THE TWO READINGS OF (19b)

a. $\quad{ }_{T P}$ nák-riian $\mathrm{T}^{0}{ }_{{ }_{v P}}{ }_{{ }_{v P}}$ mâj kin khâaw $]$ thúk-khon $\left.]\right]$

b. $\left[{ }_{T P}\right.$ nák-riian mâj $\mathrm{T}^{0}{ }_{{ } P}\left[{ }_{v P}\right.$ kin khâaw $]$ thúk-khon $\left.]\right]$

This analysis makes several desirable predictions. The higher position of negation can be disambiguated in negative past tense forms. In this case, negation scopes above FQs: 


\section{Peter Jenks}

(25)

nák-riian mâj dâj chôop kin Pahăan-farày thúk-khon

student NEG PST like eat food-Western every-CLF

'Every student didn't like to eat Western food.' $\quad * \forall>\neg, \neg>\forall$

Furthermore, VP-fronting in Thai, triggered by dâj 'can' and other modals (Visonyanggoon 2000, Simpson 2001), clearly shows that an account based on the variable position of negation is correct:

a. nákrian thúk-khon $\left[_{v \mathrm{P}} \text { klap bâan }\right]_{i}$ mâj dâj $t_{i}$ student every-CLF return home NEG can

'Every student can't return home.'

$\forall>\neg, * \neg>\forall$

b. nákrian $\left[_{v \mathrm{P}} \text { mâj klap bâan }\right]_{i}$ dâj $t_{i}$ thúk-khon

student NEG return home can every-CLF

'Every student can not return home.'

$\forall>\neg, * \neg>\forall$

c. nákrian $\left[_{v \mathrm{P}}\left[{ }_{v \mathrm{P}} \text { klap bâan }\right] \text { thúk-khon }\right]_{i}$ mâj dâj $t_{i}$

student return home every-CLF NEG can

'Every student can't return home.'

$* \forall>\neg, \neg>\forall$

d. nákrian ${ }_{{ }_{v} \mathrm{P}}$ klap bâan $]_{i}$ mâj dâj $t_{i}$ thúk-khon

student return home NEG can every-CLF

'Every student can't return home.'

$$
\forall>\neg, \neg>\forall
$$

Example (26a) shows a subject quantifier in a sentence with the negated sentencefinal modal $d \hat{a} j$, a verbal auxiliary which forces its complement to be fronted. ${ }^{3}$ In (26b) the verb is negated below the auxiliary. As clausal negation is only available when the highest auxiliary, here $d \hat{a} j$, is negated, this example must be interpreted with constituent negation on the verb. This position for negation must be interpreted under the scope of the floated quantifier. In (26c), the situation is reversed: the FQ is fronted along with the VP, and there it must scope below clausal negation on the auxiliary. This is predicted by the lower position of the FQ relative to negation before movement. Interestingly, (26b-26c) also indicate that the FQ can attach to distinct positions when multiple auxiliaries are present - a well-known property of Q-float in English and French (Sportiche 1988). Further evidence for this conclusion comes from the fact that when the subject quantifier is floated to a position after the negated modal in (26d), it again has ambiguous scope relative to negation, perhaps due to multiple positions for the FQ.

So, we can conclude, while the position of both negation and the FQ are variable, both attaching to verbs and their auxiliaries, the relative scope of these elements is directly read off their surface position. This was also true for quantifiers in subject and object position in Thai, which we saw scope rigidly relative to negation

${ }^{3}$ Note that this modal is homophonous to the 'past' form dâj in (), both grammaticalized from a homophonous verb meaning 'get,' which develops to a wide range of related meanings in Southeast Asia (Enfield 2003). 
as well. The fact that Thai Q-float has rigid scope means that it is like all other attested cases of Q-float, which have been shown to create scopally rigid structures (Williams 1982, Dowty and Brodie 1984).

\section{Quantifier Float as Quantifier Raising}

This section lays out the connection between Q-float in Thai and the semantic operation of Quantifier Raising (QR) (May 1985). Postulating syntactic movement of quantifiers (QR) accounts for a number of problems in the syntax-semantics interface, among them scopal ambiguity of sentences with multiple scope-bearing elements in English, problems in ellipsis related to Antecedent-Contained Deletion, and the mismatch between the type required by a verb of its object (type $e$ ) and the type of generalized quantifiers (type $\langle e t, t\rangle$ ) (e.g. Heim and Kratzer 1998, ch. 7).

While the traditional analysis of May (1985) analyzed QR as A-bar adjunction to $\mathrm{S}(=\mathrm{TP})$, this view was problematic because QR turns out to be "roughly clause-bound" (Reinhart 1997), while other forms of A-bar movement can apply across clauses. In response to this discrepancy, more recent analyses of QR view it as targeting the middle of the clause (Hornstein 1995, Beghelli and Stowell 1997, Johnson and Tomioka 1997, Fox and Nissenbaum 1999, Fox 2000). For subjects, this means reconstructing to their base position in $v$ P. For objects, this means scrambling to a position past the trace of the subject:

QR to the English mittelfeld

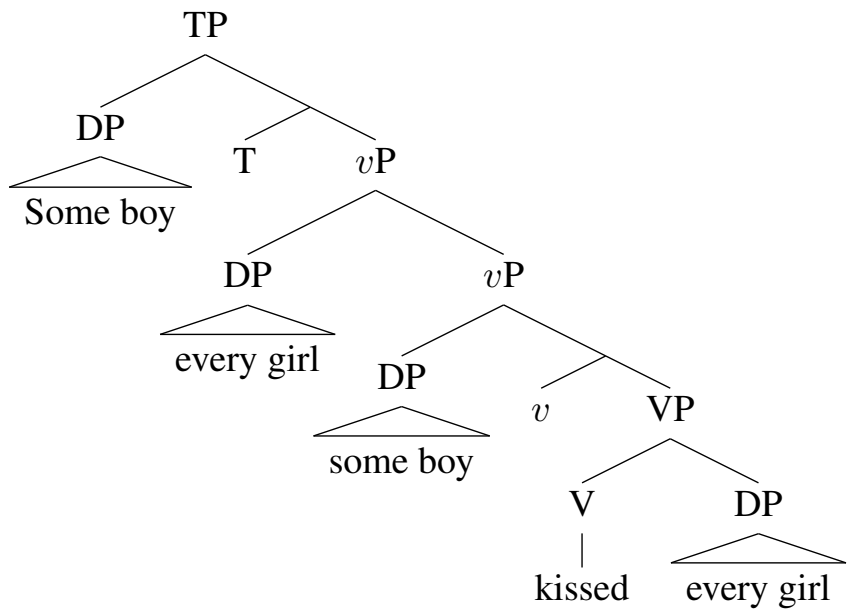

If we maintain a uniform interpretation for object quantifiers, the object-QR option in (27) is obligatory. On the other hand, whether the subject quantifier is reconstructed depends on the desired scopal interpretation of the subject.

We can translate this perspective on QR directly to the facts about Thai Q-float and scope established in the previous section. If we view the surface position of FQs as transparently reflecting the application of QR, the position of FQs adjoined to $v \mathrm{P}$, and their rigid scope, follows directly: 


\section{Peter Jenks}

a. Subject $Q$-float as $Q P$-movement

$\left[{ }_{T P}\left[\mathrm{QP}_{i}\right.\right.$ student every-CLF $]\left[{ }_{v P} t_{i}\left[{ }_{v P}\right.\right.$ read book $\left.\left.]\right]\right]$

b. Object $Q$-float as QP-movement

$\left[T P\right.$ student $\left[{ }_{v P}\left[\mathrm{QP}_{i}\right.\right.$ book every-CLF $]\left[v P\right.$ read $\left.\left.\left.t_{i}\right]\right]\right]$

In addition to accounting for the scopal effects of Q-float, positing movement also accounts for the locality restrictions $\mathrm{Q}$-float, as [Spec, $v \mathrm{P}]$ is an A-position, restricted to nominal arguments of the verb. In addition, by equating Q-float with QR, we can explain why it is such a general process in Thai, as all quantifiers must take scope. ${ }^{4}$

There are two gaping holes in the Q-float as QR analysis, though. First, while specifiers (e.g. subjects and topics) generally occur on the left in Thai, FQs occur on the right, contra the predictions of the 'reconstruction' analysis. While the $\mathrm{QR}$ analysis predicts that the nominal restriction of the FQ should occur with the FQ, it is instead occurring in its case position adjacent to the verb. In the following section, I argue that the explanation for both of these problems comes from the fact that QFs are pragmatically marked, as they always represent new, or focused, information.

\section{Quantifier Float and Focus}

It is well-known that whether information is discourse-new predicts the occurrence of phenomena such as English inversion (Birner 1994). Thai Q-float is analogous to inversion in the sense that it involves the rightward dislocation of new information. Q-float has been associated with focus in Japanese (Takami 2001, cited in Nakanishi 2008), as well as Burmese and Thai (Simpson 2011). In this section, I will expand on Simpson's evidence that Q-float in Thai is associated with focus on the quantifier. The notion of focus I am relying on here is what Kiss (1998) calls information focus, which is simply the discourse-new information provided by an utterance.

The first way of seeing that Q-float is associated with new information on the quantifier is in presentational contexts, where the existence of the relevant group or individual is being asserted (Simpson 2011, ex. 65):

\section{mii dèk maa jaanpaatîi raw sìisìp-kwàa khon}

have child come work.party around forty-plus CLF

'There were more than forty children that came to the party.'

It is important to note that these are necessarily existential, hence quantificational uses of indefinites. A sentence like (29) can be used in a context where we already know that children came to the party; only the quantifier is discourse new.

\footnotetext{
${ }^{4}$ The locality conditions on QR are different from the locality conditions on Q-float: QR allows possessors and objects of prepositions to take inverse scope, for example, a fact which May (1985) attributes to the possibility of adjunction to the XP containing the quantifier, allowing it to c-command out. I will return to this issue below
} 
Quantity questions also provide evidence that Q-float is associated with new information on the quantifier. As predicted, quantity questions and their answers are preferentially floated: ${ }^{5}$

(30) Q: nákriian chôop kin Pahăan-farày kìi-khon?

student like eat food-western how.many-CLF

'How many students like to eat western food?'

A: (nákriian chôsp kin Pahăan-farày) săam-khon student like eat food-western 3-CLF

'Three students like to eat western food.'

The quantifier can stand alone as the answer to the question above, licensing ellipsis of the rest of the sentence.

Another context where an FQ licenses ellipsis is in fragment answers to polar questions, which in Thai must be verbal elements, either verbs or a certain subclass of adjectives and adverbs, including temporal adverbs (Noss 1964, pp. 120-121):

Q: Nít chôop kin Pahăan-faràg măj?

Nit like eat food-western YNQ

'Does Nit like to eat western food?'

A: $\operatorname{chôsp~(kin)~}$

like (eat)

'Yes.'

Q: Nít kin Pahăan-farày bòoj măj?

Nit eat food-western often YNQ

'Does Nit eat western food often?'
A: (kin) bòoj
(eat) often
'Yes.'

In these two examples, the positive response to the polar question contains the new information which is affirmed by the positive response. That is to say, the questions in (31) and (32) can both be asked in a context where we already know that Nit eats western food. Thus, these question-answer pairs serve as a probe for how new information is expressed.

Turning to Q-float, FQs can also be the answer to a polar question, as expected:

$$
\begin{aligned}
& \text { Q: nákrian sòop tòk thúk-khon măj? } \\
& \text { students V:test fall every-CLF YNQ } \\
& \text { 'Did every student fail the test?' }
\end{aligned}
$$

\footnotetext{
${ }^{5}$ This answer as given would be somewhat awkward. The subject would be preferentially omitted, and, even then, repeating the sentence itself would be somewhat marked.
} 


\title{
Peter Jenks
}

\author{
A: (s’̀op tòk) thúk-khon \\ (V:test fall) every-CLF \\ 'Yes.' \\ A: ?? thúk-khon sòop tòk
}

In fact, quantifiers can be floated and serve as the answer to a polar question even when they are not floated in the question itself:

Q: nákrian thúk-khon sòop tòk mǎj? students every-CLF V:test fall YNQ

'Did every student fail the test?'
A: (sòsp tòk) thúk-khon
(V:test fall) every-CLF
'Yes.'
A: ?? thúk-khon sòop tòk

We concluded above that the positive answer to a polar question contains the content of the positive response. The fact that FQs are floated when the serve this function provides clear evidence that the floated position of the quantifier which is associated with new information.

To summarize, existential constructions, quantity questions, and polar questions all show that floated quantifiers are associated with information focus. Additional evidence could be produced, for example, from VP-ellipsis in Thai, which can strand FQs, or from texts, but I take these diagnostics to provide sufficiently strong evidence that FQs represent new information in the discourse. In the following section I lay out a proposal for how this fact might explain the two outstanding problems with the QR-based analysis of Q-float in the previous section.

\section{A Constraint-based Analysis of Quantifier Float}

Q-float structures feature a mismatch between their syntax and semantics in that the nominal host of the FQ is the restriction of the quantifier. This means that the quantifier is expected to compose with the noun before it composes with the verb to which it attaches. The choice to analyze Q-float as QR represents one of two possible solutions of this mismatch, as the QR analysis takes the surface position of the FQ to be the position where both the quantifier and its nominal host are interpreted. Evidence for this choice came from the fact that FQs were always interpreted with their surface scope. The other solution would be to propose that the quantifier was interpreted in the position of their nominal associate, but this analysis cannot account for the scopal effects of Q-float. ${ }^{6}$

\footnotetext{
${ }^{6}$ A third solution would be to claim that floated quantifiers are not quantifiers at all, but, for example, distributive operators on events. This is the main idea behind the analysis of Nakanishi (2007) and other adverbial analyses of Q-Float. While these approaches are an important alternative, I do not believe they are correct for Thai, based in no small part on the fact that the FQ so frequently includes a classifier which is clearly controlled by the nominal host of Q-float.
} 


\section{Quantifier Float, Focus, and Scope in Thai}

Thus, the QR analysis takes the noun to be adjacent to the FQ when it is interpreted. In traditional GB analyses, a typical way to analyze this kind of syntaxsemantics mismatch would be to claim that the noun moves to the position of the FQ covertly, at LF. In Minimalism, however, LF is eliminated, and covert movement arises via pronunciation of the lower copy under the copy theory of movement (Bobaljik 2002, Nunes 2004). The mechanisms regulating which copy is pronounced are varied; while there is a generally acknowledge preference for pronouncing the highest copy in a chain, some other relevant considerations include logical scope (Bobaljik and Wurmbrand 2012) and the desire to pronounce heads in positions where their features are checked (Fanselow and Ćavar 2002).

In Jenks (2011), I proposed that in analytic languages like Thai, which feature rigid SVO word order, case relations are marked by a general preference to pronounce DPs in their case positions are transparent:

(35) ARgumEnT TRAnsparency (“ArT") (Jenks 2011)

Syntactic relations must be transparently reflected at PF.

While the notion of 'transparently reflected at PF' is still somewhat ill-defined, what is relevant to the analysis of Q-float is that this preference is realized as the requirement that the nominal associate of a floated quantifier be pronounced in its canonical position.

This constraint is based on another transparency constraint, defended extensively in Bobaljik and Wurmbrand (2012), which requires transparent mapping between syntax and scopal semantics:

\section{(36) SCOPE TRANSPARENCY ("ScoT")}

If the order of two elements at LF is $\mathrm{A} \gg \mathrm{B}$, then pronounce syntactic objects which transparently reflect that order.

While Bobaljik and Wurmbrand (2012) articulate this constraint by requiring isomorphism between scope relations and phonological precedence, Thai FQs can have higher or lower scope than their preceding nominals, despite, I claim, respecting ScoT. Because of this, I state the constraint in terms of pronunciation of the syntactic copy which is interpreted, which is able to capture the rigid scope of FQs.

On their own, however, these two constraints are inadequate. Jenks (2011, ch. 6) represents an attempt to capture the attested scope effects in Thai with just these constraints, and reveals a number of undesirable predictions of this approach, such as that the lower copy of object quantifiers, in [Comp, VP], should be preferentially pronounced when object quantifiers scope under negation.

I believe that Jenks (2011) was missing any way of incorporating the relationship between focus and Q-float outlined in the previous section. I propose that this association between focus and Q-float follows from a third transparency constraint:

(37) Focus Prominence (Truckenbrodt 1995)

A focused XP is more prosodically prominent than non-focused XP. 


\section{Peter Jenks}

What counts as prosodically prominent in Thai? In the focus typology of Büring (2009), Thai is an Edge Language, where prosodic prominence is associated with the right edge of a prosodic phrase. One piece of evidence for this conclusion is Q-float itself, which we saw occurs at the right edge marking focus. FQs are just one of a larger class of elements that are focused in this position, including sentence final particles and adverbs. The effect of Focus Prominence in Thai is to derive the rightward position of FQs. Thai Q-float is thus analogous to other focusdriven rightward displacement in phenomena for which Focus Prominence has been adopted, such as subject inversion in Italian (Samek-Lodovici 2005) or Heavy NP Shift in English (Williams 2003, pp. 33-38,Bobaljik and Wurmbrand 2012).

If all three of these constraints are never violated in Thai, the scope and information structural properties of Thai Q-float fall out. Consider the examples with Q-float. We know that these cases are associated with rigid scope (section 2.3), and that they involve information focus on the quantifier (section 4). Thus, ScoT and Focus Prominence are both respected in Q-float. The role of ArT is to force the nominal associate of the floated quantifier to be pronounced in its case position.

This result can be illustrated with an OT-style tableau, where ArT, ScoT, and Focus Prominence (FoPro) are the constraints and the candidates correspond to the different possibilities for pronouncing the various copies generated by $\mathrm{QR}$ or movement to subject. This kind of analysis is illustrated below:

TABLEAU FOR Q-FLOAT FROM SUBJECT POSITION, $\neg>\mathrm{Q}$

\begin{tabular}{|ll||c|c|c|}
\hline \multicolumn{2}{|c||}{ Input:NQ [ $\neg[\mathrm{NQ}]]$} & ArT & ScoT & FoPro \\
\hline \hline a. & $\mathrm{NQ} \ldots \mathrm{NQ}$ & & & \\
\hline b. & $\mathrm{NQ} . . \mathrm{NQ}$ & & $*$ & $*$ \\
\hline c. & $\mathrm{NQ} . . . \mathrm{NQ}$ & $*$ & & \\
\hline
\end{tabular}

There are several aspects of this tableau which require clarification. The input represents the structure in $(24 b)$, where the interpretation will be one where negation scopes above the quantifier. The fact that the $\mathrm{Q}$ is bole in the input represents the fact that it is new information, thus constrained by FoPro. The crossed out elements in the candidates represent deleted copies of movement. ArT favors pronunciation of the lexical noun in its case position, which rules out the candidate in (38c). ScoT favors pronunciation of the lower (trace) copy of the subject quantifier, ruling out the non-floated variant in (38b). Candidate (38a) is thus optimal, with the caveat that the quantifier be pronounced in a prosodically prominent position, here the right edge of the clausal Intonational Phrase. Thus, Q-float in Thai represents a case of what Fanselow and Ćavar (2002) term distributed deletion, though their model of this phenomenon differs from the one I propose above, which more closely resembles the approach of Bobaljik and Wurmbrand (2012).

The remaining cases fall similarly into place. One case which was problematic for Jenks (2011) was object-oriented FQs with scope below negation. Under that 
system, from which FoPro was absent, there was no way of motivating Q-float in such cases. Under the proposal here, these cases are grammatical by virtue of the fact that the Q is focused, hence, Q-float satisfies FoPro.

A few issues deserve further mention before concluding. First, I am not confident that quantifiers cannot be in situ when they are focuses. If they can, Thai Q-float more closely resembles the cases discussed by Bobaljik and Wurmbrand (2012) where three of four combinations of scopal (here, FoPro) faithfulness and some syntactic operation are allowed, where the one impossible case is Q-float would be focus on the quantifier. Further work is needed to clarify the facts.

Second, the analysis outlined above has one more consequence, which is that it may provide an explanation for a generalization introduced in Jenks (2011, p. 307):

\section{QUANTIFIER FlOAT GENERALIZATION}

Rightward quantifier float (of $Q$-Clf) is only possible in classifier languages which allow the QP-internal order N-Q.

The basic idea is that rightward, focus-driven movement is constrained by the cyclic nature of the linearization algorithm according to the following constraint:

(40) Consistency (Fox and Pesetsky 2005, Ko 2007)

If a linear order is established within a phase, that linear order must be respected at later phases in the computation.

Thus, rightward Q-float is permitted only when it does not contradict QP-internal word order. This is because QP is a phase, and if the order $\mathrm{Q}>\mathrm{N}$ is established within a phase, that order must be respected throughout the linearization of the utterance. Thus, rightward movement of the quantifier is only permitted when the quantifier follows the noun internal to the $\mathrm{QP}$.

\section{Conclusion}

In this paper I have demonstrated that Q-float in Thai applies generally to quantificational expressions, is subject to locality restrictions, being limited to arguments, and has an adverbial distribution, where the floated quantifier receives a surface-true interpretation. We saw that these basic properties meshed well with recent analyses of $\mathrm{QR}$, which take scope-shifting operations to involve movement or reconstruction to a position around $v \mathrm{P}$.

This part of the analysis was basically identical to the analysis in Jenks (2011), but somewhat embarrassingly, had nothing to say about major properties of Q-float, including why quantifiers are separated from nouns in Q-float and why the floated quantifier appears on the right. To answer these questions, we turned to the observation that Q-float in Thai is associated with contexts where the information carried by the classifier is discourse new (Simpson 2011). Putting these different pieces together, a constraint-based analysis of Q-float was proposed where three constraints, Scope Transparency, Argument Transparency, and Focus Prominence, conspire to 


\section{Peter Jenks}

force Q-float in the appropriate discourse contexts. Interestingly, scope shift with negation and quantifiers in Thai is only possible in certain pragmatic context, a fact which support the idea that QR is sensitive to information structure (e.g. Kadmon and Roberts 1986, Erteschik-Shir 1999).

Despite the success of this analysis, its empirical scope for now is somewhat limited. There are three areas where further work is needed. First, despite the similarities between the locality restrictions on Q-float and QR, they are not identical. QR is more liberal, allowing quantifiers to scope out of the nouns that contain them in limited cases — so called cases of inverse linking (May 1985) — while Q-float does not. One way of explaining this discrepancy might be due to the linearization procedure which I argued is responsible for Q-float; because Q-float is overt, it is more restricted. Second, I have not been able to demonstrate that this analysis can be extended to account for the scopal properties of sentences with multiple quantifiers. The main reason for this is that the scopal judgments of speakers for these examples remain extremely murky, but in most cases, including in-situ subject and object quantifiers, inverse scope is a possibility, contrary to the predictions of ScoT. It thus seems that ScoT can be violated in some limited cases in Thai. Finally, the analysis I argued for here represents a departure from the major analyses of Q-float in many respects. I leave it to future work to determine to what extent my analysis might extend to languages beyond Thai.

\section{References}

Beghelli, Filippo and Stowell, Timothy, 1997. The syntax of distributivity and negation. In A. Szabolsci, ed., Ways of Scope Taking, 71-108. Dordrecht: Kluwer.

Belletti, Adriana, 1982. On the anaphoric status of the reciporical construction in Italian. The Linguistic Review 2:101-138.

Birner, Betty J., 1994. Information status and English Inversion. Language 70:233259.

Bobaljik, Jonathan, 1995. Morphosyntax: The syntax of verbal inflection. Ph.D. thesis, MIT.

Bobaljik, Jonathan, 2002. A-chains and the PF-Interface: Copies and 'Covert' Movement. Natural Language and Linguistic Theory 20:197-167.

Bobaljik, Jonathan David and Wurmbrand, Susi, 2012. Word order and scope: Transparent interfaces and the 3/4 signature. Linguistic Inquiry 43:371-421.

Boškovic̀, Zeljko and Gajewski, John, to appear. Semantic Correlates of the NP/DP Parameter. In Proceedings of NELS 39.

Büring, Daniel, 2009. Towards a typology of focus realization. In Malte Zimmerman and Caroline Féry, eds., Information Structure, 177-205. Oxford University Press.

Doetjes, Jenny, 2007. Adverbs and Quantification. Lingua 117:685-720.

Dowty, D. and Brodie, B., 1984. The Semantics of "Floated" Quantifiers in a 
Transformationless Grammar. In Proceedings of the West Coast Conference on Formal Linguistics, 75-90. CSLI Publications.

Ekniyom, P., 1982. A Study of Informational Structuring in Thai Sentences. Ph.D. thesis, University of Hawaii.

Enfield, N. J., 2003. Linguistic epidemiology: Semantics and grammar of language contact in mainland Southeast Asia. London: Roudledge Curzon.

Erteschik-Shir, Nomi, 1999. Focus Structure and Scope. In Georges Rebuschi and Laurice Tuller, eds., The Grammar of Focus, 119-150.

Fanselow, Gisbert and Ćavar, Damir, 2002. Distributed deletion. In Artemis Alexiadou, ed., Theoretical Approaches to Universals, 65-107. Philadelphia: John Benjamins.

Fox, Danny, 2000. Economy and Semantic Interpretation. Cambridge, MA: MIT Press.

Fox, Danny and Nissenbaum, Jon, 1999. Extraposition and Scope: A case for overt $Q R$. In Proceedings of the 18th West Coast Conference on Formal Linguistics, 43-54. Somerville, MA: Cascadilla Press.

Fox, Danny and Pesetsky, David, 2005. Cyclic Linerization and Syntactic Structure. Theoretical Linguistics 31:1-45.

Heim, I. and Kratzer, A., 1998. Semantics in Generative Grammar. Malden, MA: Blackwell.

Hornstein, Norbert, 1995. Logical Form: From GB to Minimalism. Cambridge, MA: Basil Blackwell.

Jenks, Peter, 2011. The hidden structure of Thai noun phrases. Ph.D. thesis, Harvard University.

Johnson, Kyle and Tomioka, Satoshi, 1997. Lowering and Mid-Size Clauses. In Graham Katz, Shin-Sook Kim, and Winhart Haike, eds., Proceedings of the Tübingen Workshop on Reconstruction, 185-206. Tūbingen, Germany.

Kadmon, Nirit and Roberts, Craige, 1986. Prosody and Scope: The Role of Discourse Structure. In CLS 22: Part 2, 16-28.

Kayne, Richard, 1984. Connectedness and Binary Branching. Cambridge, MA: MIT Press.

Kiss, Kaitlin E., 1998. Identificational focus versus information focus. Language 74(4):245-274.

Ko, Heejeong, 2007. Asymmetries in Scrambling and Cyclic Linearization. Linguistic Inquiry 38:49-83.

May, Robert, 1985. Logical Form: Its structure and derivation. Cambridge, MA: MIT Press.

Miyagawa, Shigeru, 1989. Structure and Case Marking in Japanese. New York: Academic Press.

Miyagawa, Shigeru and Arikawa, Koji, 2007. Locality in Syntax and Floating Numeral Quantifiers. Linguistic Inquiry 38:645-670.

Nakanishi, Kimiko, 2007. Measurement in the nominal and verbal domains. Linguistics and Philosophy 30:235-276. 
Peter Jenks

Nakanishi, Kimiko, 2008. The Syntax and Semantics of Floating Numeral Classifiers. In Shigeru Miyagawa and Mamoru Saito, eds., The Oxford Handbook of Japanese Linguistics. Oxford University Press.

Noss, Richard B., 1964. Thai Reference Grammar. Washington D.C.: US Foreign Service Institute.

Nunes, Jairo, 2004. Linearization of Chains and Sideward Movement. Cambridge, MA: MIT Press.

Reinhart, T., 1997. Quantifier Scope: How Labor is Divided between QR and Choice Functions. Linguistics and Philosophy 20:335-397.

Reinhart, Tanya, 1983. Anaphora and Semantic Interpretation. Chicago: University of Chicago Press.

Samek-Lodovici, Vieri, 2005. Prosody-syntax interaction in the expression offocus. Natural Language and Linguistic Theory 23:687-755.

Simpson, Andrew, 2001. Focus, Presupposition and Light Predicate Raising in Southeast Asian languages and Chinese. Journal of East Asian Linguistics 10:89-128.

Simpson, Andrew, 2004. The Syntax and Interpretation of Floating Quantifiers in Burmese and Thai. In Presentation at the 14th meeting of the Southeast Asian Linguistics Society 14.

Simpson, Andrew, 2011. Floating quantifiers in Burmese and Thai. Journal of the Southeast Asian Linguistics Society 4:114-146.

Sportiche, Dominique, 1988. A Theory of Floating Quantifiers and its Corrolaries for Constituent Structure. Linguistic Inquiry 19:425-449.

Takami, Ken-ichi, 2001. Nitieigo-no Kinooteki Koobun Bunseki [A Functional Analysis of English and Japanese Constructions]. Tokyo: Hoo Syoboo.

Truckenbrodt, Hubert, 1995. Phonological phrases: Their relation to syntax, focus, and prominence. Ph.D. thesis, MIT.

Visonyanggoon, S., 2000. Parallellism Between Noun Phrases and Clauses in Thai. Ph.D. thesis, Michigan SU.

Williams, Edwin, 1982. The NP Cycle. Linguistic Inquiry 13:277-295.

Williams, Edwin, 2003. Representation Theory. Cambridge, MA: MIT Press.

Wongbiasaj, Soranee, 1980. On Movement Transformations in Thai. Ph.D. thesis, University of Illinois.

Peter Jenks

Department of Linguistics

University of California, Berkeley

1203 Dwinelle Hall

Berkeley, CA 94720-2650

jenks@berkeley.edu 